\title{
Cepharanthine exerts antitumor activity on choroidal melanoma by reactive oxygen species production and c-Jun N-terminal kinase activation
}

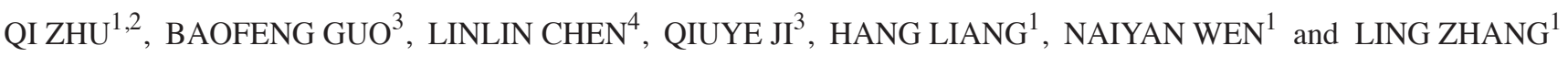 \\ ${ }^{1}$ Department of Pathophysiology, College of Basic Medicine Sciences, Jilin University, Changchun, \\ Jilin 130021; ${ }^{2}$ Department of Ophthalmology, Armed Police Force Hospital of Jilin, Changchun, Jilin 130058; \\ ${ }^{3}$ Department of Plastic Surgery, The China-Japan Union Hospital, Jilin University, Changchun, Jilin 130021; \\ ${ }^{4}$ Department of Ophthalmology, The Fourth Hospital of Shenyang, \\ Shenyang, Liaoning 110031, P.R. China
}

Received February 24, 2016; Accepted February 7, 2017

DOI: $10.3892 / 01.2017 .5945$

\begin{abstract}
Choroidal melanoma is the most common primary intraocular tumor in adults. Cepharanthine (CEP), a natural alkaloid extracted from the roots of Stephania cepharantha Hayata, has been demonstrated to inhibit the proliferation of various cancer cells. However, its potential anticancer effect in choroidal melanoma has not been clarified yet. In the present study, it was identified that CEP may potently inhibit the proliferation of human choroidal melanoma cells, induce cell death and cell cycle arrest, and activate cellular apoptotic proteins, including Bcl-2-associated X protein, caspase and poly(ADP-ribose) polymerase. Results also revealed that CEP induced the cellular production of reactive oxygen species (ROS) and led to cytochrome $c$ release, whereas concurrent treatment with N-acetyl-L-cysteine (a ROS scavenger) attenuated the situation. In addition, CEP was also revealed to activate c-Jun N-terminal kinase (JNK) 1 and 2 , whereas inhibition of $\mathrm{JNK} 1 / 2$ partially abrogated the proliferation inhibitory effect of CEP, indicating that JNK1 and JNK2 were involved in CEP-triggered cellular apoptosis. In addition, the anticancer effects of CEP were also observed in a choroidal melanoma xenograft model. In summary, the results of the present study demonstrated that CEP is effective in suppressing human choroidal melanoma cell and tumor cell proliferation, and that CEP may therefore represent a potentially novel therapeutic agent for the treatment of choroidal melanoma.
\end{abstract}

Correspondence to: Dr Ling Zhang, Department of Pathophysiology, College of Basic Medicine Sciences, Jilin University, 828 Xinmin Street, Changchun, Jilin 130021, P.R. China E-mail: lingzhangjlu@gmail.com

Key words: choroidal melanoma, cepharanthine, apoptosis, reactive oxygen species, c-Jun N-terminal kinase

\section{Introduction}

Choroidal melanoma is the most common primary intraocular tumor in adults $(1,2)$. The mean incidence of choroidal melanoma in the USA is $\sim 6$ novel cases $/ 10^{6}$ people every year (3). Currently, there are several treatment protocols for primary choroidal melanoma, including surgery, radiation therapy, thermotherapy and external beam proton therapy (4-7). The 5 -year relative survival rate of choroidal melanoma is $\sim 80 \%$ when the tumors are confined to the eyes $(3,8)$. However, patients with choroidal melanoma have a high risk of developing metastasis (typically to the liver), which is usually fatal with a median survival time of 6-9 months subsequent to the detection of liver metastasis $(3,8)$. Therefore, development of novel effective therapies for choroidal melanoma is required urgently.

Cepharanthine(CEP; 6',12'-dimethoxy-2,2'-dimethyl6,7-[methylenebis(oxy)]oxyacanthan) is a biscoclaurine alkaloid extracted from the roots of the plant Stephania cepharantha Hayata, which has been broadly used in Japan for chemoprevention and treatment of numerous diseases by virtue of its anti-inflammatory and immunomodulatory activities $(9,10)$. CEP has been reported to exert antitumor effects in numerous cancers by inhibiting cancer cell proliferation (11), cell cycle progression (12), tumor invasion (13), generating reactive oxygen species (ROS) $(11,14)$, inducing cell apoptosis $(11,14,15)$, regulating cell survival signaling pathways $(16,17)$ and increasing the competence of the host $(18,19)$. It was also identified to potentiate the anticancer effects of other chemotherapeutic agents (20-22), and was able to circumvent the multidrug resistance of doxorubicin, vincristine and other anticancer agents (21,23-26). However, little is known about the effect and molecular mechanism of CEP on choroidal melanoma.

The present study investigated the effects of CEP on choroidal melanoma cell proliferation and survival, and on a choroidal melanoma xenograft tumor. In addition, the potential underlying molecular mechanisms for CEP-induced choroidal melanoma cell apoptosis were explored. 


\section{Materials and methods}

Reagents. CEP, propidium iodide (PI) and crystal violet dye were purchased from Sigma-Aldrich (Merck KGaA, Darmstadt, Germany). CellTiter $96^{\circledR}$ AQueous One Solution reagent (MTS) was purchased from Promega Corporation (Madison, WI, USA). N-acetyl-L-cysteine (NAC) and SP600125 were purchased from Santa Cruz Biotechnology, Inc. (Dallas, TX, USA).

Cells and cell culture. The human choroidal melanoma MEL15-1 cell line was derived from a primary choroidal melanoma patient (age 60 years; female) with metastatic outcome. The human subject studies were approved by the ethical standards committee of Jilin University (Jilin, China). Written informed consent for isolating cancer cells was obtained from the patient involved in the present study. Cells were maintained in minimum essential medium supplemented with $4 \mathrm{mM}$ L-glutamine, $100 \mathrm{U} / \mathrm{ml}$ penicillin, $100 \mu \mathrm{g} / \mathrm{ml}$ streptomycin, $1 \%$ sodium pyruvate, $1 \%$ nonessential amino acids and $10 \%$ fetal bovine serum (all Corning Incorporated, Corning, NY, USA) at $37^{\circ} \mathrm{C}$ in a $5 \% \mathrm{CO}_{2}$ atmosphere.

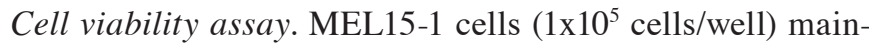
tained in minimum essential medium (Cellgro; Corning Incorporated) supplemented with $4 \mathrm{mML}$-glutamine, $100 \mathrm{U} / \mathrm{ml}$ penicillin, $100 \mu \mathrm{g} / \mathrm{ml}$ streptomycin, $1 \%$ sodium pyruvate, $1 \%$ nonessential amino acids and $10 \%$ fetal bovine serum at $37^{\circ} \mathrm{C}$, and were placed in 96-well plates overnight. CEP at various concentrations $(0,20,40,60$ and $80 \mu \mathrm{M})$, NAC, SP600125 or identical volumes of control [dimethylsulfoxide (DMSO)] was added to the appropriate wells. The cells were treated for 24 or $48 \mathrm{~h}$ prior to the addition of $20 \mu \mathrm{l}$ CellTiter 96 Aqueous One Solution reagent. Following incubation for $4 \mathrm{~h}$ at $37^{\circ} \mathrm{C}$, the number of cells in each well was determined by measuring the optical densities at $490 \mathrm{~nm}$. The results were expressed as the percentages of the control cultures.

Cell death assay. A cell death assay was performed using the Cell Death Detection ELISAPLUS kit (Roche Applied Science, Penzberg, Germany), according to the manufacturer's protocol. This photometric enzyme immunoassay was used for the quantitative in vitro determination of cytoplasmic histone-associated DNA fragments (mono- and oligonucleosomes) following induced cell death. MEL15-1 cells were treated with indicated concentrations $(0,40$ and $60 \mu \mathrm{M})$ of $\mathrm{CEP}$ at $37^{\circ} \mathrm{C}$ for $24 \mathrm{~h}$. The cell lysates were then placed into a streptavidin-coated microplate and incubated with a mixture of biotin-conjugated anti-histone and horseradish peroxidase (HRP)-conjugated anti-DNA (provided in the kit) at $15-25^{\circ} \mathrm{C}$ for $2 \mathrm{~h}$. The amount of peroxidase retained in the immunocomplex was photometrically determined with 2,2'-azinobis (3-ethylbenzothiazoline-6-sulfonic acid)-diammonium salt as the substrate. Absorbance was measured at $405 \mathrm{~nm}$. The intensity of absorbance at $405 \mathrm{~nm}$ was proportional to the amount of cell death.

Colony formation assay. Colony formation of MEL15-1 cells following drug treatment was performed as follows. Briefly, cells were seeded onto 6-well plates (1,000 cells/well), incubated at $37^{\circ} \mathrm{C}$ overnight and exposed to CEP at different concentrations $(0,40$ and $60 \mu \mathrm{M})$ for $48 \mathrm{~h}$. The cells were then incubated at $37^{\circ} \mathrm{C}$ in fresh medium for another 12-14 days. Subsequent to washing with PBS, the cells were then fixed with $10 \%$ neutral buffered formalin for $5 \mathrm{~min}$, and stained with $0.05 \%$ crystal violet solution for $30 \mathrm{~min}$.

Cell cycle analysis. Cells (1x10\% $/$ well) maintained in complete medium at $37^{\circ} \mathrm{C}$ were placed in 6-well plates overnight. CEP (40 and $60 \mu \mathrm{M}$ ), or $2 \mu \mathrm{l}$ of vehicle control (DMSO), was added to the appropriate wells. The control and treated cells were cultured for an additional $24 \mathrm{~h}$ at $37^{\circ} \mathrm{C}$, and the cells were stained with PI. Living cells were gated for cell cycle analysis. Cell cycle data were acquired using the Cell Lab Quanta ${ }^{\mathrm{TM}} \mathrm{SC}$ system (Beckman Coulter, Inc., Brea, CA, USA) and analyzed using FlowJo software (version 9.9.5; Tree Star, Inc., Ashland, OR, USA).

Western blot analysis. Whole cell lysates were prepared by using radioimmunoprecipitation assay buffer (1\% NP-40, $0.5 \%$ sodium deoxycholate and $0.1 \%$ SDS in PBS) supplemented with 100X protease inhibitor cocktail (Roche Applied Science) and phosphatase inhibitor cocktail (Cell Signaling Technology, Inc., Danvers, MA, USA). The mitochondrial and cytosolic fractions were separated using the digitonin method (27). Briefly, $5 \times 10^{6}$ cells $(200 \mu \mathrm{l})$ were permeabilized on ice with $21.33 \mu \mathrm{g}$ digitonin (Sigma-Aldrich; Merck KGaA) in $80 \mu \mathrm{l}$ buffer containing $75 \mathrm{mM} \mathrm{NaCl}, 8 \mathrm{mM} \mathrm{Na}_{2} \mathrm{HPO}_{4}$, $1 \mathrm{mM} \mathrm{NaH}_{2} \mathrm{PO}_{4}$ and $250 \mathrm{mM}$ sucrose, supplemented with $100 \mathrm{X}$ protease inhibitor cocktail and phosphatase inhibitors. Following incubation for $30 \mathrm{sec}$ in ice cold buffer, cells were centrifuged at $4^{\circ} \mathrm{C}$ for $2 \mathrm{~min}$ at $13,000 \mathrm{x} \mathrm{g}$. The supernatant was removed as the cytosolic fraction, and the remaining pellet was resuspended in the same volume of buffer not containing digitonin. A total of $20 \mu \mathrm{l}$ of Laemmli sample buffer (Sigma-Aldrich; Merck KGaA) supplemented with $10 \%$ dithiothreitol and $10 \%$ SDS was added to all samples. Protein samples were analyzed by SDS-PAGE (12\% gels) and blotted onto the polyvinylidene fluoride membrane (GE Healthcare Life Sciences, Chalfont, UK). Primary antibodies used were specific to: B-cell lymphoma 2 (Bcl-2; catalog no. 2872), Bcl-2-associated X protein (Bax; catalog no. 2774), caspase-3 (catalog no. 9662) cleaved caspase-3 (catalog no. 9661), caspase-9 (catalog no. 9502), cleaved caspase-9 (catalog no. 9505), cleaved poly (ADP-ribose) polymerase(PARP) (catalog no. 9542), phosphorylated c-Jun N-terminal kinase (JNK; Thr ${ }^{183} / \mathrm{Tyr}^{185}$ ) (catalog no. 9251) (1:1,000; all from Cell Signaling Technology, Inc., Danvers, MA, USA), cytochrome c (cyt c) $(1: 2,000 ;$ catalog no. ab13575), JNK1 (1:2,000; catalog no. ab110724;), JNK2 (1:2,000; catalog no. ab76125) (all from Abcam, Cambridge, UK) and $\beta$-actin $(1: 8,000$; catalog no. SAB5500001; Sigma-Aldrich; Merck KGaA). The HRP-conjugated anti-mouse (1:4,000; catalog no. sc-2371) and anti-rabbit secondary antibodies (1:4,000; catalog no. sc-2357) were purchased from Santa Cruz Biotechnology, Inc. (Dallas, TX, USA). Signals were detected using the Immun-Star HRP peroxide luminol/enhancer kit (Bio-Rad Laboratories, Inc., Hercules, CA, USA). Quantification of the western blots was performed using ImageJ software (National Institutes of Health, Bethesda, MD, USA). 
Luminescence assay/detection of ROS. The detection of ROS was performed using the ROS-Glo ${ }^{\mathrm{TM}}$ assay (Promega Corporation) according to the manufacturer's protocol. Cells treated with CEP in combination with or without NAC for $24 \mathrm{~h}$ were incubated with ROS-Glo ${ }^{\mathrm{TM}} \mathrm{H}_{2} \mathrm{O}_{2}$ substrate for $6 \mathrm{~h}$ at $37^{\circ} \mathrm{C}$. The ROS-Glo ${ }^{\mathrm{TM}}$ detection solution was then added and the plate was incubated for $20 \mathrm{~min}$ at room temperature. The luminescence was measured using a SpectraMax L microplate reader (Molecular Devices, LCC, Sunnyvale, CA, USA). The intensity of luminescence was proportional to the amount of ROS.

Nude mice and tumor inoculations. The protocol was approved by the Committee on the Ethics of Animal Experiments of Jilin University. Mice were sacrificed by $\mathrm{CO}_{2}$ asphyxiation followed by cervical dislocation when they became moribund and when they reached defined study end points. The present study was performed in accordance with the recommendations from the Institutional Animal Care and Use Committee of Jilin University. A total of 24 male athymic nude mice (Charles River Laboratories, Inc., Wilmington, MA, USA) purchased at 4 weeks of age with $\sim 20 \mathrm{~g}$ weight were kept under sterile conditions in a pathogen-free environment. The mice were provided with sterile water and food ad libitum. All manipulations were carried out aseptically inside a laminar flow hood. The xenograft model was established in the nude mice using cells. Briefly, tumor cells $\left(1 \times 10^{6}\right)$ were suspended in $0.1 \mathrm{ml}$ serum-free medium and injected into the subcutaneous tissue of 6-week-old nude mice using a 27 -gauge needle. Tumors were allowed to grow for 10 days prior to treatment. The mice were then divided into 4 groups, each of 6 mice with similar mean tumor volumes (between 100 and $150 \mathrm{~mm}^{3}$ ).

In vivo treatment protocol. When solid tumors grew to $100-150 \mathrm{~mm}^{3}$, mice were treated with vehicle control or CEP $(25 \mathrm{mg} / \mathrm{kg})$ for 4 weeks (5 times/week) via peritumoral injection. The tumors were measured every 3 days and the relative tumor volumes were calculated. At 27 days, mice were sacrificed by $\mathrm{CO}_{2}$ asphyxiation followed by cervical dislocation.

Statistical analysis. All quantitative data are presented as the mean \pm standard deviation. Statistical tests were performed with the SPSS software package (version 19.0; IBM SPSS, Armonk, NY, USA). Differences between two groups were tested using paired Student's t-tests. $\mathrm{P}<0.05$ was considered to indicate a statistically significant difference.

\section{Results}

CEP inhibits MEL15-1 cell proliferation and induces MEL15-1 cell death. A large body of evidence demonstrated that CEP effectively inhibits various cancer cell lines (11,12,14-17). To test whether CEP may also inhibit MEL15-1 cell proliferation, MEL15-1 cells were treated with CEP at various concentrations $(0,20,40,60$ and $80 \mu \mathrm{M})$ for 24 or $48 \mathrm{~h}$, and then subjected to an MTS assay. Results demonstrated that CEP was able to dose-dependently inhibit cell proliferation with a half-maximal inhibitory concentration of 40-60 $\mu \mathrm{M}$ (Fig. 1A). Treatment with CEP (40 and $60 \mu \mathrm{M}$ ) for $24 \mathrm{~h}$ was also revealed to markedly suppress colony formation and induce cell death of MEL15-1 cells compared with the vehicle control (Fig. 1B and C). To investigate how CEP affects MEL15-1 cell proliferation, cell cycle analysis was performed following MEL15-1 cell exposure to $24 \mathrm{~h}$ treatment with CEP (40 and $60 \mu \mathrm{M})$. Results demonstrated that treatment with CEP at 40 and $60 \mu \mathrm{M}$ induced $\mathrm{G} 2$ arrest (31.7 and 35.5\%, respectively) compared with the vehicle control (14.0\%) (Fig. 1D).

CEP induces apoptosis in MEL15-1 cells via the caspase signaling pathway. To analyze whether CEP induces MEL15-1 cell cytotoxicity by triggering the apoptotic process, the expression levels of the pro-apoptotic protein Bax and the anti-apoptotic protein Bcl-2 were examined. The results revealed that, following CEP treatment for $24 \mathrm{~h}$, the expression levels of Bax in MEL15-1 cells were markedly increased, whereas the levels of Bcl-2 were significantly decreased (Fig. 2). Since enhanced Bax/Bcl-2 ratio is known as an activator of caspase-3 $(28,29)$, the effects of CEP on caspase-associated proteins were analyzed. The results revealed that procaspase-3, procaspase-9 and PARP were decreased dose-dependently in MEL15-1 cells treated with CEP (Fig. 2). By contrast, increased levels of active (cleaved) caspase-3, caspase-9 and PARP were observed in cells treated with CEP (Fig. 2) compared with control cells.

CEP induces cellular ROS production and cyt c release from mitochondria. Previous studies have demonstrated that CEP inhibits cancer cell proliferation by inducing ROS production $(11,14)$. Therefore, in the present study, it was hypothesized that CEP induces MEL15-1 cells via affecting cellular ROS production. ROS production was measured in MEL15-1 cells following $24 \mathrm{~h}$ treatment with $\mathrm{CEP}(0-60 \mu \mathrm{M})$ in the presence or the absence of $5 \mathrm{mM}$ NAC (a commonly used antioxidant). Results demonstrated that treatment with CEP significantly induced cellular ROS production compared with the vehicle control, whereas concurrent treatment with NAC attenuated this effect (Fig. 3A).

Considering the aforementioned observation and the evidence that ROS production is associated with mitochondria function, it was investigated whether CEP-induced cell death resulted from the effect of CEP on mitochondria function. It was revealed that cyt $c$ was released from mitochondria in MEL15-1 cells following between 2 and $4 \mathrm{~h}$ treatment with $40 \mu \mathrm{M}$ CEP, whereas concurrent treatment with $5 \mathrm{mM}$ NAC prevented this event (Fig. 3B and C). These results indicated that CEP triggers MEL15-1 cell apoptosis through the mitochondrial signaling pathway by inducing ROS production.

Proliferation inhibitory effects of CEP on MEL15-1 cells are mediated by activation of the JNK signaling pathway. The JNK signaling pathway is known to be a pro-apoptotic signaling pathway and has been identified to be implicated in CEP-induced apoptosis in other tumor cells $(14,30)$. Aiming at dissection of the molecular mechanism of the antitumor effects of CEP in MEL, the regulation of CEP on the JNK signaling pathway was examined using western blot analysis. Activation (phosphorylation) of JNK1 and JNK2 was observed following CEP treatment (Fig. 4A and B). Such activation was abolished by the co-treatment with CEP and SP600125, a novel and 

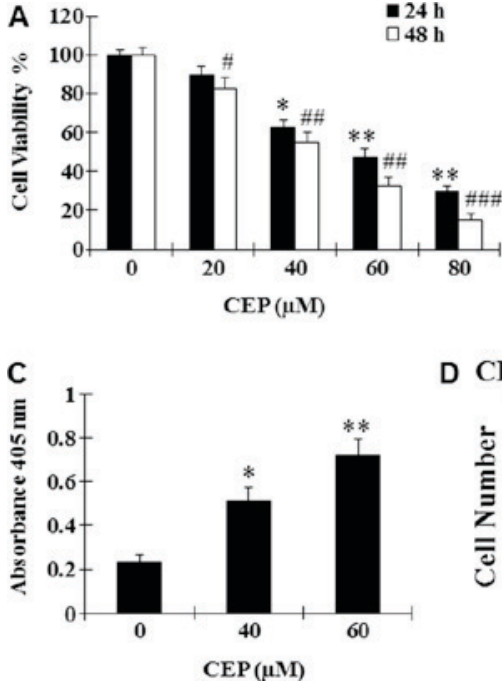

$\mathrm{B}$ CEP $(\mu \mathrm{M}) \quad 0$

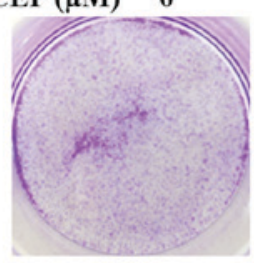

40
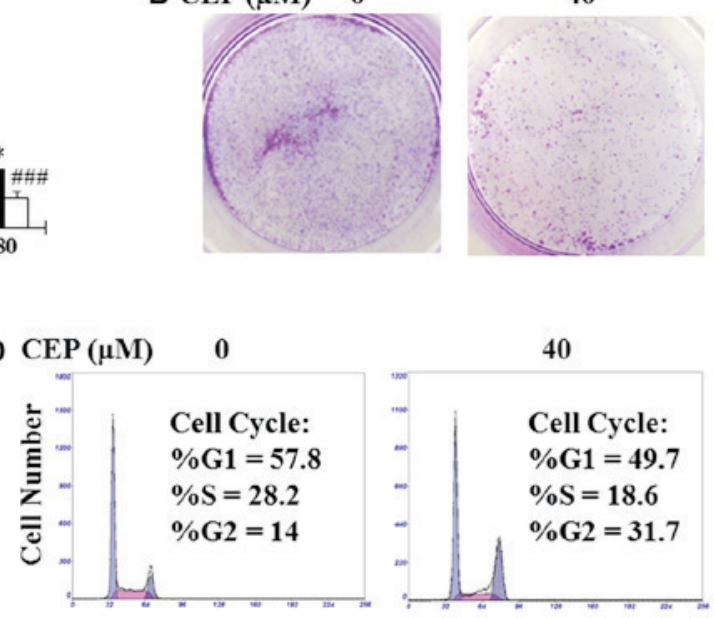

40

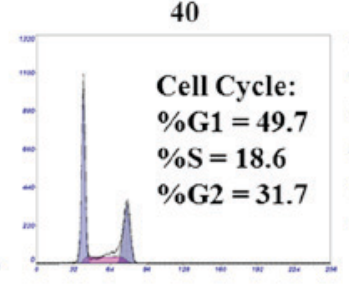

DNA Content
60

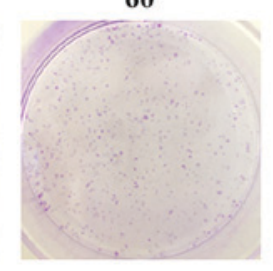

60

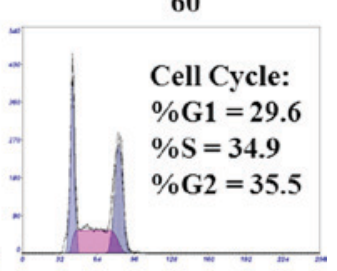

Figure 1. Inhibitory effects of CEP on MEL15-1 cells. (A) Cell viability assay of MEL15-1 cells treated with between 0 and $80 \mu \mathrm{M}$ CEP for 24 or 48 h. Cell viability following drug treatment was calculated as a percentage relative to control groups. Data represent the mean \pm SD from three separate experiments. (B) Colony formation of MEL15-1 cells treated with 0,40 and $60 \mu \mathrm{M}$ CEP. Data are representative of one of three separate experiments. (C) Cell death assay of MEL15-1 cells treated with 0,40 and $60 \mu \mathrm{M} \mathrm{CEP}$ for $24 \mathrm{~h}$. Data represent the mean \pm SD from three separate experiments. (D) Cell cycle analysis of MEL15-1 cells treated with 0,40 and $60 \mu \mathrm{M}$ CEP for $24 \mathrm{~h}$. Data are representative of one of three separate experiments. ${ }^{*} \mathrm{P}<0.05,{ }^{* *} \mathrm{P}<0.01$ vs. control; ${ }^{\#} \mathrm{P}<0.05,{ }^{\# \#} \mathrm{P}<0.01$,

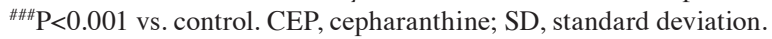

A

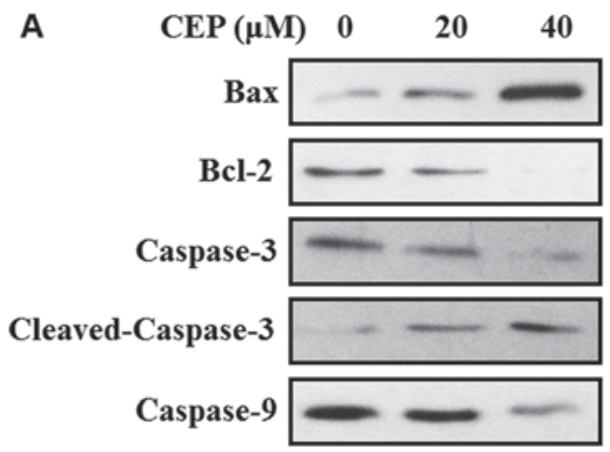

Cleaved-Caspase-9
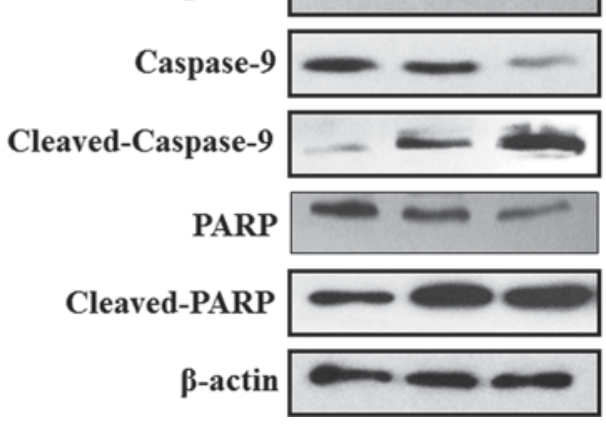

PARP
B

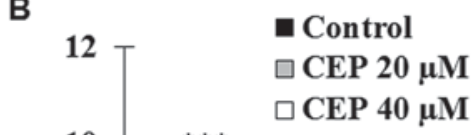

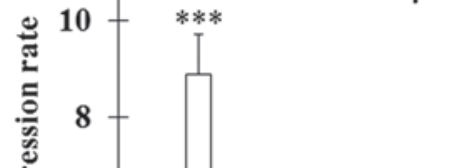

Figure 2. CEP induces apoptosis in MEL15-1 cells via the caspase signaling pathway. (A) Western blot analysis of apoptotic proteins from MEL15-1 cells treated with 0, 40 and $60 \mu \mathrm{M}$ CEP for $24 \mathrm{~h}$. (B) Quantification of protein expression rate. Protein expression rate in control groups were normalized to 1. $\beta$-Actin served as a loading control. Data represent the mean \pm standard deviation from three separate experiments. ${ }^{*} \mathrm{P}<0.05 ;{ }^{* * *} \mathrm{P}<0.01 ;{ }^{* * *} \mathrm{P}<0.001$ vs. control. CEP, cepharanthine; Bcl-2, B-cell lymphoma-2; Bax, Bcl-2-associated X protein; PARP, poly(ADP-ribose) polymerase.

selective inhibitor of JNK (31) (Fig. 4A and B). In addition, the ROS scavenger NAC significantly decreased the CEP-induced phosphorylation of JNK1/2 (Fig. 4A and B), indicating that the activation of the JNK signaling pathway is dependent on ROS production.

To further analyze whether CEP exerts the inhibitory effects on MEL15-1 cells, dependent on ROS production and the JNK signaling pathway, MEL15-1 cells were treated with CEP in combination with or without the ROS scavenger NAC and the JNK inhibitor SP600125. The results demonstrated that NAC and SP600125 reversed the CEP-induced inhibition on MEL15-1 cell viability (Fig. 4C).
Inhibitory effects of CEP on tumor growth. Mice were treated with $25 \mathrm{mg} / \mathrm{kg}$ doses of CEP for 4 weeks (5 times/week) and tumor growth was measured during the treatment period. Statistically significant growth inhibition was seen with CEP treatment when compared with the control (Fig. 5A). No significant loss in body weight was observed in mice treated with CEP (Fig. 5B). To examine whether CEP induces MEL15-1 cell apoptosis and regulates the JNK signaling pathway in vivo, the expression of proteins in the caspase signaling pathway and JNK signaling pathway in tumor tissues treated with or without CEP was analyzed. Consistent with the in vitro results of the present study, increased levels of active (cleaved) 


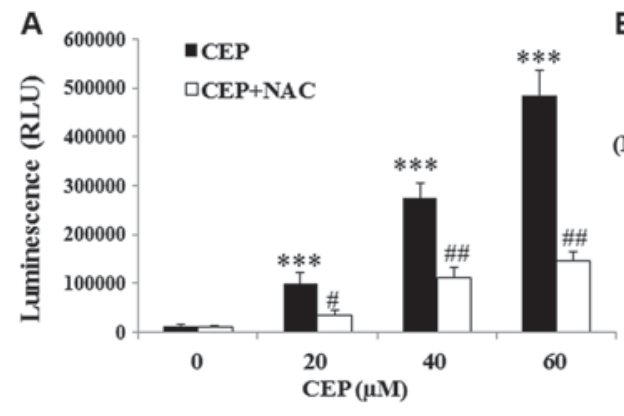

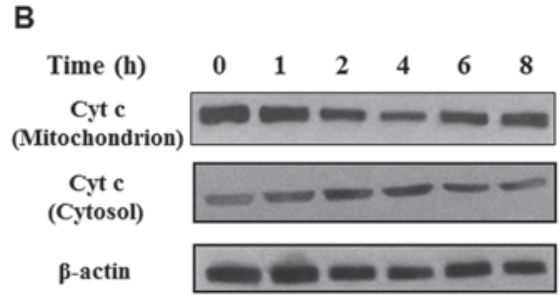

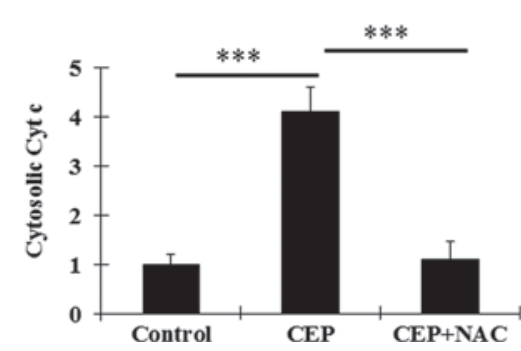

C

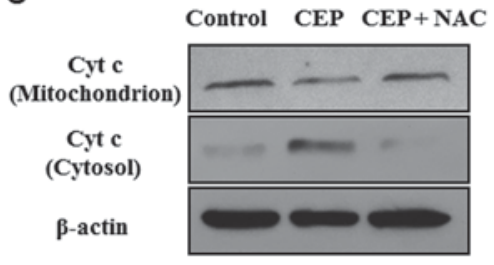

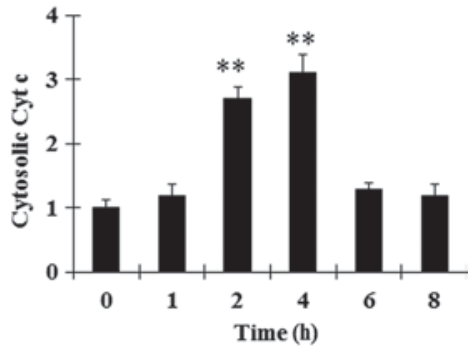

Figure 3. CEP induces cellular ROS production and cyt $c$ release from mitochondria. (A) Detection of ROS production of MEL15-1 cells treated with between 0 and $60 \mu \mathrm{M}$ CEP in combination with or without $5 \mathrm{mM}$ NAC for $24 \mathrm{~h}$. Data represent the mean \pm SD from three separate experiments. (B) Western blot analysis of cyt $c$ from MEL15-1 cells treated with $40 \mu \mathrm{M} \mathrm{CEP}$ at various time points, and quantification of cyt $c$ expression rate. (C) Western blot analysis of cyt $c$ from MEL15-1 cells treated with $40 \mu \mathrm{M}$ CEP with or without $5 \mathrm{mM} \mathrm{NAC}$ at $4 \mathrm{~h}$, and quantification of cyt $c$ expression rate. Protein expression rate in control groups was normalized to 1 . $\beta$-Actin served as a loading control. Data are presented as the mean $\pm \mathrm{SD}$ from three separate experiments. ${ }^{* *} \mathrm{P}<0.01$, ${ }^{* * * *} \mathrm{P}<0.001$ vs. control; $\mathrm{P}<0.05,{ }^{\# \#} \mathrm{P}<0.01$ vs. control. $\mathrm{SD}$, standard deviation; cyt $c$, cyctochrome $c$; ROS, reactive oxygen species; CEP, cepharanthine; NAC, $\mathrm{N}$-acetyl-L-cysteine; RLU, relative light units.
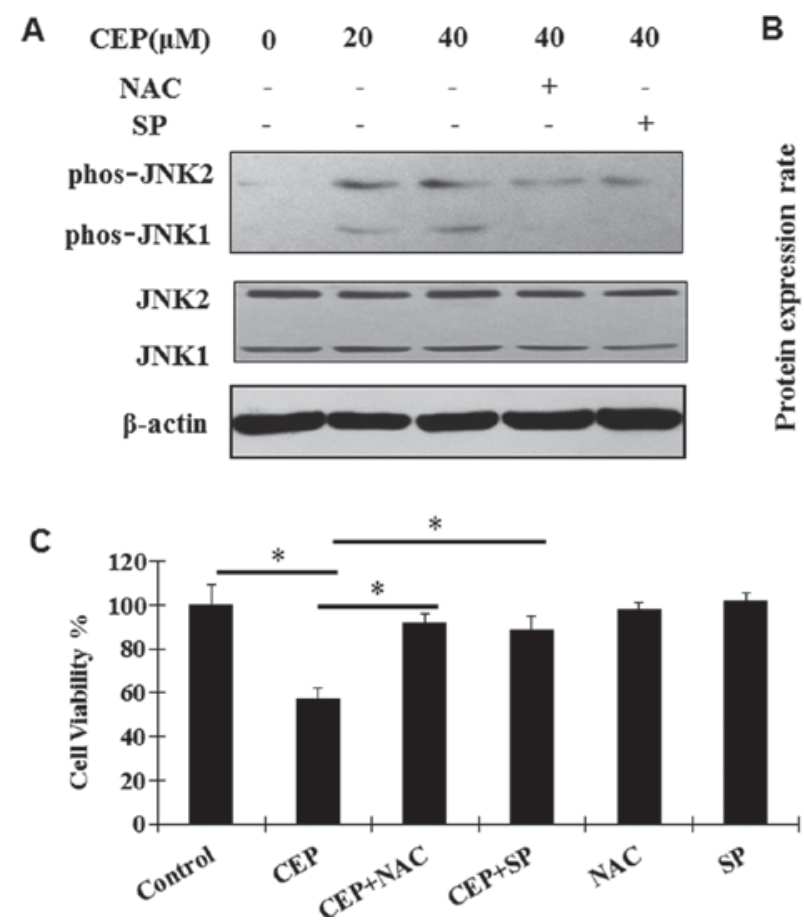

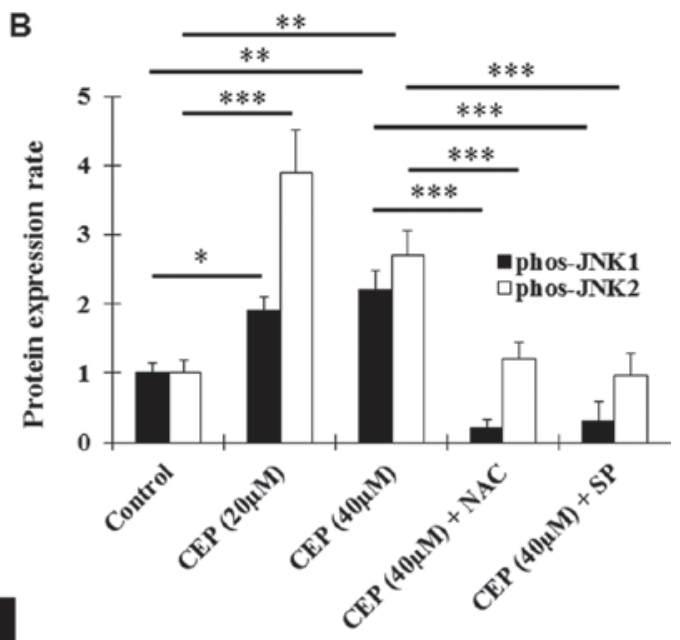

Figure 4. Proliferation inhibitory effect of CEP on MEL15-1 cells is mediated by JNK signaling pathway activation. (A) Western blot analysis of JNK and phos-JNK from MEL15-1 cells treated with CEP with or without $5 \mathrm{mM} \mathrm{NAC}$ or $2 \mu \mathrm{M}$ SP600125 for $24 \mathrm{~h}$. (B) Quantification of protein expression rate. The protein expression rate in the control groups was normalized to 1 . $\beta$-actin served as a loading control. Data are presented as the mean $\pm \mathrm{SD}$ from three separate experiments. (C) Cell viability assay of MEL15-1 cells treated with $40 \mu \mathrm{M}$ CEP in combination with or without $5 \mathrm{mM}$ NAC or $2 \mu \mathrm{M}$ SP600125 for $48 \mathrm{~h}$. Cell viability following drug treatment was calculated as a percentage relative to control groups. Data are presented as mean the \pm SD from three separate experiments. ${ }^{*} \mathrm{P}<0.05 ;{ }^{* * *} \mathrm{P}<0.01 ;{ }^{* * *} \mathrm{P}<0.001$. SD, standard deviation; CEP, cepharanthine; NAC, N-acetyl-L-cysteine; JNK, c-Jun N-terminal kinase; phos-JNK, phosphorylated JNK; SP, SP600125.

caspase-3, caspase-9 and PARP were observed in tumors treated with CEP compared with those treated with vehicle control. Activation (phosphorylation) of JNK1 and JNK2 was also observed upon CEP treatment (Fig. 5C).

\section{Discussion}

The results of the present study demonstrated that CEP, a natural alkaloid extracted from the roots of S. cepharantha 
A

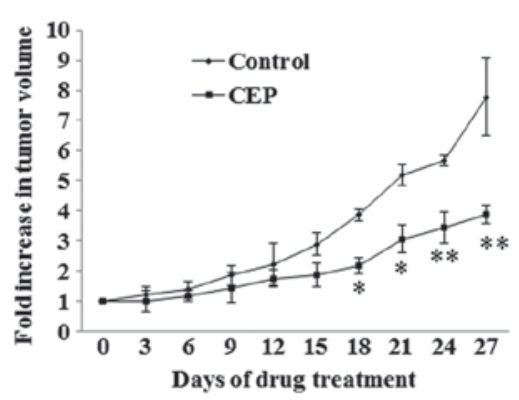

B

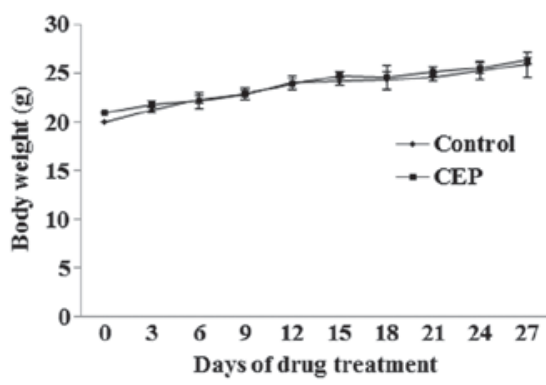

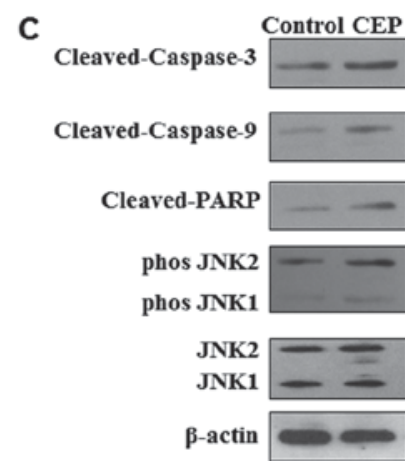

Figure 5. Effect of CEP on choroidal melanoma tumor growth in nude mice. (A) Effect of CEP on xenograft tumor volume. (B) Effect of CEP on nude mice body weight. Mice were treated with vehicle control or CEP $(25 \mathrm{mg} / \mathrm{kg}$ ) for 4 weeks ( 5 times/week) by peritumoral injection. Data are presented as the mean \pm standard deviation from three separate experiments. Each group contained 6 mice. ${ }^{*} \mathrm{P}<0.05 ;{ }^{* *} \mathrm{P}<0.01$ vs. control. (C) Western blot analysis of caspase proteins, JNK and phos-JNK in tumor tissue from mice treated with or without CEP. $\beta$-Actin served as a loading control. CEP, cepharanthine; JNK, c-Jun N-terminal kinase; phos-JNK, phosphorylated JNK.

Hayata, potently suppresses the proliferation of choroidal melanoma cells, induces cell cycle arrest and activates cellular apoptotic proteins, including Bax, caspase and PARP. The results of the present study also revealed that CEP induced the production of ROS and led to cyt $c$ release, whereas the ROS scavenger NAC was able to attenuate the situation. In addition, consistent with a previous study (14), CEP was also revealed to activate JNK1 and JNK2 (members of the mitogen-activated protein kinase pathway), which may serve an important role in CEP induced apoptosis.

In the present study, it was demonstrated that CEP induces MEL15-1 cell apoptosis in a dose-dependent manner. The Bcl-2 protein family is known to control the commitment of cells to apoptosis (32). The increased expression level of Bax and a reduced level of Bcl-2, as well as increased levels of cleaved caspase- 3 and caspase- 9 , induced by CEP treatment in MEL15-1 cells indicated that CEP-induced apoptosis occurs via the activation of caspase- 3 and caspase- 9 and the mitochondrial pathways. In addition, consistent with previous studies of CEP in other cancer cells $(11,14)$, the results demonstrated that the production of ROS increased in CEP-treated MEL15-1 cells. The excessive production of ROS is likely due to stimuli that act on the Bcl-2 family protein, subsequently altering the mitochondrial membrane integrity. This was substantiated by the observation that CEP induced the release of cyt $c$ from mitochondria.

JNK activation has been revealed to lead to apoptosis and correlate positively with oxidative stress-induced apoptosis (33-35). The activation of JNK was also revealed to be implicated in CEP-triggered apoptosis in human hepatocellular carcinoma cells (14). In the present study, it was observed that ROS and JNK activation are positively associated with the anticancer effects of CEP in MEL15-1 cells. Notably, the results of the present study revealed that treatment with the ROS scavenger NAC may abolish the activation of JNK in MEL15-1 cells and the inhibitory effects of CEP on cell viability, indicating that CEP-induced JNK activation is ROS-dependent. Other functional consequences for CEP-induced ROS, as well as JNK activation, are not yet established and require additional investigation.

CEP, as a natural alkaloid extract, has been demonstrated to effectively inhibit the proliferation of various cancer cell lines (9-11,14-17). Notably, it was also revealed to possess anti-metastasis activity against different types of cancer cells $(13,36)$. CEP was demonstrated to suppress invasion and migration of cholangiocarcinoma cells, possibly by suppressing intercellular adhesion molecule-1 and matrix metalloproteinase-2 (13). Intraperitoneal injection of CEP was reported to inhibit the metastasis of Lewis lung carcinoma in a mouse model (37), and CEP inhibited metastasis of human colon cancer cells in a mouse model (36). In addition, the combination of CEP and other chemotherapeutic agents, including 5 -fluorouracil, or recombinant human interferon- $\beta$ or $-\gamma$, were demonstrated to be even more effective to prevent metastasis $(36,37)$. In the present study, the inhibitory effects of CEP on primary choroidal melanoma tumor growth were observed. Since metastasis remains a life-threatening risk for choroidal melanoma (38), future studies will focus on the effect of CEP (alone or in combination with other agents) on metastasis of choroidal melanoma using a metastatic choroidal melanoma model to develop a safe and effective regimen for choroidal melanoma therapy.

\section{Acknowledgements}

The present study was funded by the National Natural Science Foundation of China (grant nos. 81201188 and 81472344) and the International Cooperation Project of Jilin Provincial Science and Technology Department (grant no. 20150414031GH).

\section{References}

1. Laver NV, McLaughlin ME and Duker JS: Ocular melanoma. Arch Pathol Lab Med 134: 1778-1784, 2010.

2. Singh AD, Turell ME and Topham AK: Uveal melanoma: Trends in incidence, treatment, and survival. Ophthalmology 118: 1881-1885, 2011.

3. Singh P and Singh A: Choroidal melanoma. Oman J Ophthalmol 5: 3-9, 2012

4. Finger PT: Radiation therapy for choroidal melanoma. Surv Ophthalmol 42: 215-232, 1997.

5. Finger PT: Transpupillary thermotherapy in choroidal melanoma Ophthalmology 104: 731-732, 1997.

6. Oosterhuis JA, Journée-de Korver HG and Keunen JE: Transpupillary thermotherapy: Results in 50 patients with choroidal melanoma. Arch Ophthalmol 116: 157-162, 1998.

7. Wilson MW and Hungerford JL: Comparison of episcleral plaque and proton beam radiation therapy for the treatment of choroidal melanoma. Ophthalmology 106: 1579-1587, 1999. 
8. Gragoudas ES, Egan KM, Seddon JM, Glynn RJ, Walsh SM, Finn SM, Munzenrider JE and Spar MD: Survival of patients with metastases from uveal melanoma. Ophthalmology 98 383-390, 1991

9. Rogosnitzky M and Danks R: Therapeutic potential of the biscoclaurine alkaloid, cepharanthine, for a range of clinical conditions. Pharmacol Rep 63: 337-347, 2011.

10. Gulcin I, Elias R, Gepdiremen A, Chea A and Topal F: Antioxidant activity of bisbenzylisoquinoline alkaloids from Stephania rotunda: Cepharanthine and fangchinoline. J Enzyme Inhib Med Chem 25: 44-53, 2010.

11. Furusawa S, Wu J, Fujimura T, Nakano S, Nemoto S, Takayanagi M, Sasaki K and Takayanagi Y: Cepharanthine inhibits proliferation of cancer cells by inducing apoptosis. Methods Find Exp Clin Pharmacol 20: 87-97, 1998.

12. Kikukawa Y, Okuno Y, Tatetsu H, Nakamura M, Harada N, Ueno S, Kamizaki Y, Mitsuya H and Hata H: Induction of cell cycle arrest and apoptosis in myeloma cells by cepharanthine, a biscoclaurine alkaloid. Int J Oncol 33: 807-814, 2008

13. Uthaisar K, Seubwai W, Srikoon P, Vaeteewoottacharn K, Sawanyawisuth K, Okada S and Wongkham S: Cepharanthine suppresses metastatic potential of human cholangiocarcinoma cell lines. Asian Pac J Cancer Prev 13 (Suppl): S149-S154, 2012.

14. Biswas KK, Tancharoen S, Sarker KP, Kawahara K, Hashiguchi T and Maruyama I: Cepharanthine triggers apoptosis in a human hepatocellular carcinoma cell line (HuH-7) through the activation of JNK1/2 and the downregulation of Akt. FEBS Lett 580: 703-710, 2006.

15. Wu J, Suzuki H, Zhou YW, Liu W, Yoshihara M, Kato M, Akhand AA, Hayakawa A, Takeuchi K, Hossain K, et al: Cepharanthine activates caspases and induces apoptosis in Jurkat and K562 human leukemia cell lines. J Cell Biochem 82: 200-214, 2001.

16. Chen Z, Huang C, Yang YL, Ding Y, Ou-Yang HQ, Zhang YY and Xu M: Inhibition of the STAT3 signaling pathway is involved in the antitumor activity of cepharanthine in SaOS2 cells. Acta Pharmacol Sin 33: 101-108, 2012.

17. Seubwai W, Vaeteewoottacharn K, Hiyoshi M, Suzu S, Puapairoj A, Wongkham C, Okada S and Wongkham S: Cepharanthine exerts antitumor activity on cholangiocarcinoma by inhibiting NF-kappaB. Cancer Sci 101: 1590-1595, 2010.

18. Morioka S, Ono M, Tanaka N and Orita K: Synergistic activation of rat alveolar macrophages by cepharanthine and OK-432. Gan To Kagaku Ryoho 12: 1470-1475, 1985 (In Japanese).

19. Furusawa $S$ and Wu J: The effects of biscoclaurine alkaloid cepharanthine on mammalian cells: Implications for cancer, shock, and inflammatory diseases. Life Sci 80: 1073-1079, 2007.

20. Ita M, Halicka HD, Tanaka T, Kurose A, Ardelt B, Shogen K and Darzynkiewicz Z: Remarkable enhancement of cytotoxicity of onconase and cepharanthine when used in combination on various tumor cell lines. Cancer Biol Ther 7: 1104-1108, 2008.

21. Kato T and Suzumura Y: Potentiation of antitumor activity of vincristine by the biscoclaurine alkaloid cepharanthine. J Natl Cancer Inst 79: 527-532, 1987

22. Harada K, Ferdous T, Itashiki Y, Takii M, Mano T, Mori Y and Ueyama Y: Effects of cepharanthine alone and in combination with fluoropyrimidine anticancer agent, $\mathrm{S}-1$, on tumor growth of human oral squamous cell carcinoma xenografts in nude mice. Anticancer Res 29: 1263-1270, 2009.
23. Kisara S, Furusawa S, Murata R, Ogata M, Hikichi N, Takayanagi Y and Sasaki K: Combined effects of buthionine sulfoximine and cepharanthine on cytotoxic activity of doxorubicin to multidrug-resistant cells. Oncol Res 7: 191-200, 1995.

24. Zhou Y, Hopper-Borge E, Shen T, Huang XC, Shi Z, Kuang YH, Furukawa T, Akiyama S, Peng XX, Ashby CR Jr, et al: Cepharanthine is a potent reversal agent for MRP7 (ABCC10)-mediated multidrug resistance. Biochem Pharmacol 77: 993-1001, 2009.

25. Shiraishi N, Akiyama S, Nakagawa M, Kobayashi M and Kuwano M: Effect of bisbenzylisoquinoline (biscoclaurine) alkaloids on multidrug resistance in $\mathrm{KB}$ human cancer cells. Cancer Res 47: 2413-2416, 1987.

26. Hotta T, Tanimura H, Yamaue H, Iwahashi M, Tani M, Tsunoda T, Noguchi K, Mizobata S and Terasawa H: Synergistic effects of tamoxifen and cepharanthine for circumventing the multidrug resistance. Cancer Lett 107: 117-123, 1996.

27. Single B, Leist M and Nicotera P: Simultaneous release of adenylate kinase and cytochrome $\mathrm{c}$ in cell death. Cell Death Differ 5: 1001-1003, 1998

28. Salakou S, Kardamakis D, Tsamandas AC, Zolota V, Apostolakis E, Tzelepi V, Papathanasopoulos P, Bonikos DS, Papapetropoulos T, Petsas T and Dougenis D: Increased $\mathrm{Bax} / \mathrm{Bcl}-2$ ratio up-regulates caspase-3 and increases apoptosis in the thymus of patients with myasthenia gravis. In Vivo 21: 123-132, 2007.

29. Yang B, Johnson TS, Thomas GL, Watson PF, Wagner B, Furness PN and El Nahas AM: A shift in the Bax/Bcl-2 balance may activate caspase-3 and modulate apoptosis in experimental glomerulonephritis. Kidney Int 62: 1301-1313, 2002.

30. Dhanasekaran DN and Reddy EP: JNK signaling in apoptosis. Oncogene 27: 6245-6251, 2008.

31. Bennett BL, Sasaki DT, Murray BW, O'Leary EC, Sakata ST, Xu W, Leisten JC, Motiwala A, Pierce S, Satoh Y, et al: SP600125, an anthrapyrazolone inhibitor of Jun N-terminal kinase. Proc Natl Acad Sci USA 98: 13681-13686, 2001.

32. Czabotar PE, Lessene G, Strasser A and Adams JM: Control of apoptosis by the BCL-2 protein family: Implications for physiology and therapy. Nat Rev Mol Cell Biol 15: 49-63, 2014

33. Shen HM and Liu ZG: JNK signaling pathway is a key modulator in cell death mediated by reactive oxygen and nitrogen species. Free Radic Biol Med 40: 928-939, 2006.

34. Nakano H, Nakajima A, Sakon-Komazawa S, Piao JH, Xue X and Okumura K: Reactive oxygen species mediate crosstalk between NF-kappaB and JNK. Cell Death Differ 13: 730-737, 2006.

35. Son Y, Cheong YK, Kim NH, Chung HT, Kang DG and Pae HO: Mitogen-activated protein kinases and reactive oxygen species: How Can ROS activate MAPK pathways? J Signal Transduct 2011: 792639, 2011.

36. Ono M, Tanaka N and Orita K: Positive interactions between human interferon and cepharanthin against human cancer cells in vitro and in vivo. Cancer Chemother Pharmacol 35: 10-16, 1994.

37. Ito $\mathrm{H}$, Ito $\mathrm{H}$, Amano $\mathrm{H}$ and Noda $\mathrm{H}$ : Inhibitory effect of a biscoclaurine alkaloid, cepharanthin, on lung metastasis of Lewis lung carcinoma. Jpn J Pharmacol 56: 195-202, 1991

38. Rietschel P, Panageas KS, Hanlon C, Patel A, Abramson DH and Chapman PB: Variates of survival in metastatic uveal melanoma. J Clin Oncol 23: 8076-8080, 2005. 